\title{
Vivência da Morte de Idosos na Percepção de um Grupo de Médicos: Conversas sobre a Formação Acadêmica*
}

\author{
The Experience of Death among the Elderly \\ in the Eyes of a Group of Physicians: Talking \\ about Medical Training
}

Sadi Poletto

Janaína Rigo Santin

Luiz Antonio Bettinelli ${ }^{\text {II }}$

PALAVRAS-CHAVE:

- Morte;

- Formação Acadêmica;

- Ortotanásia

- Ética.

KEYWORDS:

- Death;

- Education;

- Orthothanasia;

- Ethics.

Recebido em: 13/10/2012

Reencaminhado em: 22/01/2013

Aprovado em: 26/02/2013

REVISTA BRASILEIRA DE EDUCAÇÃO MÉDICA $186 \frac{27(2): 186-191 ; 2013}{30}$
"Este trabalho foi elaborado a partir da Dissertação de Mestrado do Programa de Pós-Graduação em Envelhecimento Humano da Universidade de Passo Fundo - RS, apresentada no dia 28 de março de 2012.

I Universidade de Caxias do Sul, Caxias do Sul, RS, Brasil.

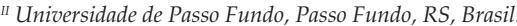




\section{INTRODUÇÃO}

A opção de não prolongar o sofrimento de uma vida eminentemente no limiar é um problema delicado, que exige intenso discernimento,, criterioso diálogo e uma tomada de decisão consciente por parte da equipe de saúde. Entretanto, tradicionalmente, o médico foi treinado na sua formação para manter a vida e vencer a morte.

Acredita-se que, quando não há mais tratamento para a cura, não há mais o que fazer pelo paciente. Assim, devido à ampla produção dos recursos para a manutenção da vida, é de extrema significância o empenho para resguardar a dignidade humana no momento da morte. "Quando retrocedemos no tempo e estudamos culturas e povos antigos, temos a impressão de que o homem sempre abominou a morte e, provavelmente, sempre a repeliu"1.

Considerando as descrições na literatura sobre a morte desde a Antiguidade até nossos dias, observam-se as variáveis na aceitação da morte e o morrer no decorrer do tempo ${ }^{2}$.

Este estudo se detém nas percepções do limiar da vida e suas relações com o aprendizado nos cursos de graduação em medicina. O que se ensina nos meios acadêmicos é que a morte faz parte do cotidiano médico, porém esse tema é pouco discutido durante a formação do profissional. O relato de vivências demonstra os caminhos trilhados no aprendizado pelos entrevistados da pesquisa, as dificuldades na abordagem e possíveis alternativas para discussão de um tema tão sensível e difícil nos dias atuais. Demonstra-se quando a referência do aprendizado acadêmico sobre assuntos como o limiar da vida e a passagem para a morte é tênue nos meios de ensino em alguns cursos de medicina.

A relevância da pesquisa se estabelece quando as percepções evidenciadas respondem a um novo olhar orientado para modificações de atitudes sociais e culturais. Considera-se este estudo significativo para compreender a vivência médica no processo de morte e morrer, constatando-se que, no ensino de graduação em medicina, a abordagem do tema limita-se frequentemente em valorizar a manutenção da vida, e não de como lidar com a morte no processo evolutivo da terminalidade de seus pacientes.

Dentro dessa perspectiva, a busca por respostas levou aos seguintes questionamentos: qual o significado da morte de um paciente idoso? E como foi o processo de formação acadêmica, considerando a questão da abordagem de pacientes terminais e/ou no processo de morte e morrer?

Para responder a esses questionamentos tem-se como objetivo do estudo: conhecer as vivências e abordagens de médicos, envolvendo o processo de morte e morrer de pacientes idosos no ambiente hospitalar.

\section{MÉTODO}

O estudo foi exploratório com abordagem qualitativa. A coleta de dados realizou-se através de entrevista individual semiestruturada. As entrevistas foram gravadas em meio eletrônico de áudio e transcritas para fins de análise. A técnica empregada foi a análise temática de Bardin ${ }^{3}$, adaptada por Minayo ${ }^{4}$.

Foram entrevistados 11 médicos que atuam há pelo menos cinco anos em um hospital geral de grande porte no interior do Rio Grande do Sul, atendendo várias especialidades da clínica médica e clínica cirúrgica, porém que não fossem intensivistas, e que atendessem a pacientes idosos. Sete eram do sexo masculino e quatro do sexo feminino. Um participante era viúvo e dez eram casados. Dez eram católicos e um espírita. A média de idade foi de 51,09 anos, estando na faixa etária entre 39 e 63 anos. A média de tempo de formado foi de 27,09 anos, estando no período entre 16 e 38 anos de formados. Todos eram de etnia branca. Todos fizeram pós-graduação em sua área. Cinco sofreram perda de familiares com terminalidade prolongada, e seis não referiram essa perda. Dois conheciam totalmente o código de ética médica vigente e nove parcialmente. Um conhecia o Estatuto do Idoso totalmente, sete parcialmente e três não conheciam o documento. Seis tiveram sua formação na graduação em instituições de ensino superior particulares, dois em escolas federais da capital e três em federais do interior do estado do Rio Grande do Sul.

Os dados obtidos após a transcrição das entrevistas foram tratados a partir da técnica de análise temática, através da codificação e interpretação, buscando conhecer as informações que se apresentam nos discursos analisados. A análise temática se desenvolveu em três diferentes fases: a pré-análise, em que se organiza o material empírico, sistematizando as ideias iniciais e criando as subcategorias e categorias; a exploração do material, que define as categorias de análise, foram realizadas as operações de busca e separação do material empírico; e, por fim, a fase de tratamento dos resultados obtidos e sua interpretação, em que os materiais brutos são tratados de maneira a serem significativos e válidos aos interesses da pesquisa realizada.

Os participantes receberam informações a respeito da instituição de origem da pesquisa, objetivo do estudo e foi lido o Termo de Consentimento Livre e Esclarecido (TCLE). Após $\mathrm{o}$ aceite, o TCLE foi assinado em duas vias, ficando uma com o pesquisador e outra com o participante. O projeto obteve aprovação do Comitê de Ética em Pesquisa da Universidade de Passo Fundo, sob o registro no CEP 097/2011, CAAE n ${ }^{\circ}$ 0008.0.398.000-11. 


\section{RESULTADOS}

Os dados coletados através da entrevista individual foram categorizados, possibilitando a construção das categorias: vivências na formação acadêmica; sugerindo mudanças na formação; e omissão no ensino médico.

\section{Vivências na Formação Acadêmica}

Nas instituições de graduação de onde os profissionais médicos participantes do estudo são oriundos, pouco se discutiu sobre o tema, priorizando-se o uso de tecnologias e tratamentos para tentar afastar a morte, apregoando-se a imortalidade. Esse aspecto pouco ou nada favorece o enfrentamento da morte por parte dos profissionais envolvidos, quando têm que fazê-lo.

Assim se manifestaram os participantes:

\begin{abstract}
"Em todo curso de medicina não me foi falado absolutamente nada sobre a morte. Nunca ninguém perguntou para mim e para nenhum dos meus colegas da época qual a relação que tinha com a morte. [...] O médico fez a faculdade, recebeu a formação teórica e alguma coisa da prática e é jogado no mundo com o poder de vida e de morte; e esse poder de vida e de morte sem que ele nunca tenha trabalhado a sua relação com isso". (E1)

"A única coisa que eu me lembro de comentar sobre morte era na cadeira de medicina legal com um professor que era espírita. [...] Ele que foi a única pessoa que comentou morte e morrer na verdade né. A relação com a morte foi a única pessoa porque o resto esconde".

\section{Sugerindo Mudanças na Formação}

Dentro do panorama demonstrado na categoria anterior, os participantes manifestaram a necessidade de que o tema do processo de morte e morrer fosse discutido durante a formação profissional.

“Eu não faria cadeiras, eu faria que todos os alunos pelo menos até em grupo fizessem psicoterapia. Todos os alunos durante o curso frequentassem uma psicoterapia, que poderia ser em grupo. A pessoa faria a sua psicoterapia que seria em grupo, mas com orientação e curando as suas dores". (E1)

"A segunda coisa que eu faria é a volta do preceptor, mas não o preceptor técnico. Aquele preceptor onde a pessoa acompanha na visita diária e ele vai sentar na beira do leito e vai conversar com a família, vai conversar com o paciente e vai decidir as coisas e não com o laboratório ou o computador. E para isso se tivesse que colocar alguma cadeira na faculdade eu colocaria terapia de família. Não é medicina de família, é terapia de família onde o médico começaria a ver de forma sistêmica o conjunto das pessoas que o procuram". (E11)

[...] "eu penso que deveria existir sempre na formação um acompanhamento do paciente e que o médico participasse da equipe multidisciplinar. O médico muitas vezes não participa da equipe multidisciplinar que atende aquele paciente. Então por exemplo, o paciente é atendido pelo psicólogo isoladamente, pela enfermeira isoladamente, pelo médico isoladamente, só que as percepções dessas pessoas o médico não quer saber [...]. Então na formação médica o importante seria que o médico ele fosse colocado junto com a equipe multidisciplinar pra fazer o atendimento. E também outra que o médico tivesse aula sobre a terminalidade, tivesse psicologia, eu acho que seria muito importante um médico ter aprendizado em terminalidade pelo âmbito da psicologia, pelo âmbito da religião, pelo âmbito da própria medicina". (E6)

\section{Omissão no Ensino Médico sobre Morte e Morrer}

Quanto à sua formação médica no que tange a abordagem e o enfrentamento que tiveram sobre a morte e o morrer, os participantes foram unânimes em afirmar que os cursos foram omissos, não oportunizando o debate sobre o tema. Houve manifestações de que durante a formação houve o ocultamento da morte, valorizando sobremaneira a cura.

Os participantes mencionaram que a abordagem do tema durante a formação foi insignificante, trazendo dilemas éticos quando do exercício profissional.

"[...] isso é uma falha da faculdade, dos cursos de medicina, que eu encaro como sendo uma falha, porque na verdade todos nós somos instruídos a salvar. Todos nós somos instruídos a fazer tudo o que é possível pelo paciente. O possível e o impossível para a manutenção da vida, e ninguém nos conta que nossos pacientes vão morrer sim, que tem fim e que chega uma hora que a gente tem que admitir que chegou um fim e que a gente tem que parar [...]". (E3)

"[...] se a medicina com o decorrer do tempo não rever os conceitos do que é a medicina hoje, nós teremos, no mercado de trabalho, vários profissionais totalmente desatualizados, totalmente desqualificados. Eu acho que os bancos da faculdade se não reverem conceitos e práticas médicas de que o médico não pode tudo e que a caneta pode tudo isto, nós cada vez colocamos médicos, não médicos no mercado, mas doutores em que se diz que sabem tudo e na realidade não sabem nada, principalmente a parte humana que é pouco ensinada". (E4) 


\section{DISCUSSÃO}

Estudos de Dickinson ${ }^{5}$, em 2006, afirmam que das 122 escolas médicas nos Estados Unidos, 100\% oferecem aulas sobre morte e morrer e $94 \%$, sobre cuidados paliativos.

Refletindo sobre o ensino médico da morte e do morrer, Kovács ${ }^{6}$ faz referência ao que outros autores chamam de "aprendizagem experiencial", a qual se reflete quando da contextualização das entrevistas sobre vivências na formação acadêmica. Assim, a criação de cursos de tanatologia (estudo da morte) é muito importante por várias razões. Uma delas é a "necessidade de espaços estruturados num contexto pedagógico permitindo a exploração e discussão de temas fortemente carregados, como é o caso da morte e do luto". A mesma autora menciona outra razão sobre o estudo da morte é o aprendizado experiencial, como descrito numa entrevista onde o filho estudante acompanhava o pai médico. A educação para a morte está ligada estritamente ao contexto interpessoal no qual ela ocorre. Quando se trata de um modelo de aprendizagem experiencial, a pessoa está envolvida em um processo ativo, que pode ter efeitos mais duradouros.

O ensino nos cursos de medicina procedeu a uma troca da destreza em realizar anamneses elucidativas e o exame físico detalhado, sendo substituído pela precisão das informações fornecidas pelos equipamentos. O que era complementar transformou-se em essencial ${ }^{7}$.

Fica bem explícito nas falas das entrevistas o despreparo da vivência de morte no decorrer dos cursos de medicina devido à carência do estudo desse assunto na prática acadêmica. A aprendizagem sobre morte é uma experiência para toda a vida. Segundo Kovács ${ }^{6}$, o estudo objetiva remover as dificuldades que se apresentam quando se discute o tema, trazendo o indivíduo para a reflexão sobre perdas e o processo vital, que é um conteúdo tão difícil de ser abordado no dia a dia.

Para alguns entrevistados há falhas no aprendizado, pois afirmam que ninguém ensina nos cursos de graduação por eles realizados que o paciente está no final da vida e vai morrer. Os entrevistados mencionaram ainda a ausência da temática morte na formação acadêmica. Isso também foi evidenciado por estudo semelhante realizado por Bifulco ${ }^{8}$, no qual a ausência da temática morte na formação acadêmica dos profissionais foi sentida em sua totalidade.

Kovács ${ }^{6}$ cita que Knot e colaboradores elaboraram um livro de atividades com o objetivo de facilitar a comunicação sobre o tema da morte. Os pontos básicos apontados na obra são os seguintes: "Ajudar a clarificar crenças, sentimentos, comportamentos sobre o que é prioritário em nossas vidas. Oferecer expectativas bastante realistas que permitam algum controle e qualidade sobre a vida. Permitir o diálogo e favorecer as providências num momento tão difícil como é o momento da morte, numa época muito influenciada pela tecnologia".

Santos ${ }^{9}$ menciona que os profissionais da saúde deveriam ter disciplinas, na graduação, que contemplassem no seu conteúdo a discussão sobre a educação para a morte, preparando-os para lidar com a morte daqueles que estão sob seu cuidado. O autor pergunta como é possível oferecer esse preparo. Na subcategoria "sugerindo mudanças na formação", a sugestão é de cadeiras específicas sobre o assunto, bem como o uso da psicoterapia para curar suas próprias dores e medos.

Azeredo et al. ${ }^{10}$ confirmam o que expressou uma entrevista da pesquisa: somente inserir conteúdos pedagógicos sobre morte não é a solução. Fixar-se somente na teoria não é suficiente. É necessário incluir vivências do cotidiano prático com discussões sobre o assunto de forma continuada.

Algumas falas das entrevistas enfocam de maneira clara um ponto crucial na deficiência do aprendizado sobre morte, na vida acadêmica, quando relatam uma outra perspectiva no trato com a família:

"[...] eu colocaria terapia de família. Não é medicina de família, é terapia de família onde o médico começaria a ver de forma sistêmica o conjunto das pessoas que o procuram".

Isso delimita uma dificuldade que o profissional enfrenta ao ter que vivenciar a experiência de dar a "má notícia" à família, quando não teve experiências com esses fatos, nem preparação na sua vida acadêmica, orientada por um preceptor.

A educação para a morte solidifica-se com o conteúdo de Kovács ${ }^{11}$, que aponta para algumas formas de discussão e proposições para o aprendizado e a vivência experiencial da terminalidade para profissionais da educação e saúde. Isso fica evidente quando os participantes da pesquisa manifestam que deveria existir um acompanhamento do paciente por uma equipe multidisciplinar da qual médico participasse, o que ampliaria sua vivência e conhecimentos além da medicina.

Outros estudos evidenciam achados que confirmam a citação de uma entrevista que diz:

\footnotetext{
"Na teoria o papel aceita tudo. Acho que tinha que dá era na prática. O papel tem um monte de coisas no papel que te diz. Mas e no dia a dia, mas e na prática? A prática seria indispensável. Eu não tive isso nem na faculdade e nem na residência. Sempre preparados para a vida [...]". (E5)
}

Confirmam-se os argumentos de Bifulco ${ }^{8}$ referindo-se à necessidade de vivências pessoais em relação à temática da morte e aos cuidados paliativos nos cursos de graduação. 
Para alguns participantes das entrevistas, o estudo da terminalidade deveria ter cadeira específica na faculdade. $\mathrm{O}$ entendimento do Código de Ética Médica mereceria uma aplicação prática, para transportar o conteúdo para o aprendizado acadêmico, o que determinaria uma visão mais global sobre o assunto. Alguns visualizam o aprendizado sobre terminalidade com um olhar filosófico e cultural.

O necessário olhar da multidisciplinaridade também se evidencia nas manifestações dos entrevistados, quando referem o envolvimento das especialidades médicas nas suas condutas e percepções sobre a morte e o morrer envolvendo o paciente e a família. Isso reafirma algumas manifestações que solidificam a ideia de que os acadêmicos de medicina precisam vivenciar tudo isso.

As manifestações têm um ponto central, o qual se refere à necessidade de inserir, no contexto do projeto pedagógico dos cursos da saúde, afins com a morte e o morrer, informações que favoreçam o convívio dos profissionais com a terminalidade. Esse aprendizado tem várias sugestões que se extraem dos segmentos de falas apresentados, que vão desde disciplinas regulares até livros e vivências experienciais nas práticas de enfermaria.

A categoria "conversas sobre a formação acadêmica" deixa bem clara a importância da experiência acadêmica relacionada à finitude. Dois fios condutores definem-se nas afirmativas das entrevistas: omissão do assunto no ensino médico e sugestões de mudanças nesse mesmo ensino.

\section{CONSIDERAÇÕES}

Dois pontos se sobressaem na observação das manifestações deste artigo. Há necessidade de os cursos de graduação da área da saúde contemplar vivências experienciais, com a necessária revisão curricular sobre o estudo da morte.

O campo de estudo sobre a finitude tem uma palavra que se aplica no próprio conceito filológico da antítese, que é a infinitude desse questionamento. Isso posto, parece claro que o assunto não está encerrado. Ampliar a discussão e envolver partes que convivem com a morte e o morrer são de relevância fundamental. Um estudo de amplitude maior seria próprio para solidificar conceitos que ainda necessitam de afirmações mais seguras, embora já exista o ordenamento jurídico próprio, como é o caso do Estatuto do Idoso, do Código de Ética Médica, bem como dos conteúdos da bioética e do biodireito.

Este estudo mostrou que a relação profissional-paciente deve ser diferente, valorizando-se cada ser humano e respeitando o princípio da dignidade. Esses aspectos permitirão a humanização do cuidado, e essa prática estará embasada no novo Código de Ética Médica e nos princípios de bioética.
A consciência da problemática que envolve o cotidiano do profissional médico em relação aos aspectos do limite da vida/morte é um dilema que oferece subsídios para muitas reflexões, podendo gerar discussões com vistas a encontrar estratégias de enfrentamento nesse momento limítrofe na vida de cada ser humano. Foi possível apreender significados do processo de morte e morrer, permitindo criar situações inquietantes na vida de cada profissional, propiciando refletir e redirecionar um novo agir, e buscar a transformação do cuidado nesse momento difícil de cada ser humano.

É necessário encontrar caminhos, utilizando atitudes menos rotineiras, às vezes mecânicas e impessoais, para que se consiga construir vínculos no cuidado aos pacientes e familiares nos momentos que antecedem e sucedem a sua morte. Entretanto, é bom lembrar que os profissionais médicos necessitam de suporte para melhor enfrentamento da morte de seus pacientes. Outra iniciativa é criar ambientes com base na solidariedade humana, que respeitem a dignidade dos pacientes e familiares em todos os momentos de cuidado, inclusive na morte.

É importante pontuar alguns aspectos que são significativos no desenvolvimento de novos estudos sobre a temática. Essa discussão sobre o tema deve extrapolar a categoria médica, atingindo todos os profissionais da saúde em uma abordagem interdisciplinar, envolvendo também outros segmentos da sociedade.

Há necessidade de rever os currículos dos cursos de graduação de medicina e áreas afins, para privilegiar também o aspecto relativo ao processo de morte e morrer, bem como cuidados paliativos de pacientes, muito embora alguns deles já incluam no conteúdo pedagógico o estudo da bioética.

Nessa perspectiva, é importante salientar que o médico precisa ter a consciência de sua condição humana e, através dela, ser orientado a perceber a complexidade da realidade do cuidado, o sentido e o significado da vida de todas as pessoas envolvidas nesse processo.

Essa realidade no processo de formação e aprendizado médico estimula a reflexão sobre a abordagem no processo de morte e morrer. Assim, é mister a criação de espaços de discussão durante a formação médica sobre a abordagem e enfrentamento da morte. Esses espaços poderão minimizar os dilemas éticos enfrentados no cotidiano de trabalho dos futuros profissionais da medicina.

\section{Observação:}

As partes das entrevistas citadas neste trabalho foram mantidas sem modificações ou correções conforme as falas transcritas das gravações. 


\section{REFERÊNCIAS}

1. Kübler-Ross E. Sobre a morte e o morrer. $8^{\underline{a}}$ ed. São Paulo: Martins Fontes; 2005. p. 296.

2. Ariès P. O homem diante da morte. $2^{\underline{a}}$ ed. Rio de Janeiro: Francisco Alves; 1989.

3. Bardin L. Análise de conteúdo. Lisboa: Edições 70; 2008.

4. Minayo MC de S. O desafio do conhecimento: pesquisa qualitativa em saúde. 8a ed. São Paulo: Hucitec; 2004. p. 269.

5. Dickinson GE. Teaching end-of-life issues in US medical schools: 1975 to 2005. AmJhospice palliative care [periodico na internet]. 2006 [acesso em 13 set. 2012];23(3):197204. Disponível em: http://www.ncbi.nlm.nih.gov/pubmed/17060279

6. Kovácks MJ. Morte e existência humana: caminhos de cuidados e possibilidades de intervenção.. Rio de Janeiro: Guanabara Koogan; 2008. p. 222.

7. Siqueira JE. Reflexões éticas sobre o cuidar na terminalidade da vida. Bioética. 2005;13(2):37-50.

8. Bifulco VA, Iochida LC. A formação na graduação dos profissionais de saúde e a educação para o cuidado de pacientes fora de recursos terapêuticos de cura. Rev Bras Educ Med.[periódico na internet]. 2009 [acesso em 13 set. 2012];33(1):92-100. Disponível em: http://www.scielo.
br/scielo.php?pid=S0100-55022009000100013\&script=sci abstract\&tlng=pt

9. Santos FS. Cuidados paliativos: discutindo a vida, a morte e o morrer. São Paulo: Atheneu;2009. p. 447.

10. Azeredo NSG, Rocha CF, Carvalho PRA. Formação de acadêmicos de medicina. Rev Bras Educ Med. 2011;35(1):3743.

11. Kovács MJ. Educação para a morte. PsicolcCiênc profissão. 2005;25(3):484-97.

\section{CONTRIBUIÇÃO DOS AUTORES}

Os dois co-autores auxiliaram na discussão da estrutura do artigo e revisoes de suas modificações.

\section{CONFLITO DE INTERESSES}

Declarou não haver.

\section{ENDEREÇO PARA CORRESPONDÊNCIA}

Sadi Poletto

Rua Saldanha Marinho, 435, Galeria Solar sala 809

Centro - Bento Gonçalves

CEP. 95700-000 RS

E-mail: sadi@poletto.med.br 